\title{
Late Stage Cervical Cancer among Confırmed Cervical Cancer Cases in a Tertiary Care Centre: A Descriptive Cross-sectional Study
}

\author{
Neebha Ojha, ${ }^{1}$ Meena Jha, ${ }^{2}$ Eliza Shrestha, ${ }^{3}$ Ganesh Dangal ${ }^{4}$ \\ 'Department of Obstetrics and Gynaecology, Tribhuvan University, Institute of Medicine, Kathmandu, Nepal, \\ ${ }^{2}$ Paropakar Maternity \& Women's Hospital, Kathmandu, Nepal, '² Department of Obstetrics and Gynaecology, \\ Bhaktapur Cancer Hospital, Kathmandu, Nepal, ${ }^{4}$ Department of Obstetrics and Gynaecology, Kathmandu \\ Model Hospital, Kathmandu, Nepal.
}

\section{ABSTRACT}

Introduction: Cervical cancer is the leading gynaecological cancer in Nepal. Most of the time, it is diagnosed in the late stage with its associated morbidity and mortality. This study aimed to find out the prevalence of late-stage presentation of cervical cancer among confirmed cases of cervical cancer in a tertiary care centre.

Methods: A descriptive cross-sectional study was conducted at a tertiary care centre of Nepal from March 2021 to May 2021 after obtaining ethical clearance from the Institutional Review Board (Reference no.805). A convenient sampling method was used. A descriptive analysis was done of all cases of cervical cancer who were diagnosed within the last 36 months and attended hospital during the study period. The information was collected by interview and hospital record was checked. Analysis was done using Statistical Package for Social Sciences version 20. Point estimate at 95\% Confidence Interval was calculated along with frequency and proportion for binary data.

Results: Among the 142 confirmed cervical cancer cases, the prevalence of late-stage presentation of cervical cancer was 93 (65.5\%) (57.7-73.3 at 95\% Confidence Interval). The mean age at diagnosis was $50.6 \pm 10.9$ years. More than two-thirds of the women were from outside Kathmandu valley 102 $(71.8 \%)$ and came from $>50 \mathrm{~km}$ distance. The majority of the women $83(58.5 \%)$ were illiterate.

Conclusions: The study showed that two-thirds of the women presented in advanced stage and the factors leading to the late stage. This highlights the fact, that the focus should be on the provision of organized screening programs and early diagnosis and treatment of cervical cancer.

Keywords: cervical cancer; clinical factors; demographic factors; late-stage; Nepal.

\section{INTRODUCTION}

Globally cervical cancer is the fourth most frequent cancer in females and represents $6.6 \%$ of all female cancers. ${ }^{1}$ However, in Nepal it is the most common cancer in females. ${ }^{2}$ More than $90 \%$ of cervical cancers occur in developing countries. ${ }^{3}$ Approximately $84 \%$ of all cervical cancers and $88 \%$ of all deaths caused by cervical cancer occurred in lower-resource countries. ${ }^{1}$

A study in two cancer hospitals of Nepal showed $80.9 \%$ of cervical cancer had late-stage presentation. ${ }^{4}$ Factors such as race, age at diagnosis, marital status, ${ }^{5}$ educational status, ${ }^{6}$ places of residence, ${ }^{7}$ number of children, $^{8}$ and screening practices $^{9}$ have been associated with the late-stage presentation of cervical cancer. Knowing the burden of late-stage presentation of cervical cancer may provide a base on which appropriate steps for prevention and treatment can be planned.

This study aimed to find out the prevalence of latestage presentation of cervical cancer among confirmed cases of cervical cancer in a tertiary care centre.

Correspondence: Dr. Neebha Ojha, Department of Obstetrics and Gynecology, Tribhuvan University, Institute of Medicine, Maharajguni, Kathmandu, Nepal. Email: neebha. ojha@gmail.com, Phone: +977-9841288377. 
Ojha et al. Late Stage Cervical Cancer among Confirmed Cervical Cancer Cases in a Tertiary Care Centre: A Descriptive Cross-sectional Study...

\section{METHODS}

This is a descriptive cross-sectional study conducted at Bhaktapur Cancer Hospital, Nepal from March 2021 to May 2021. Ethical approval was taken from the Institutional Review Board (Ref no.805). Convenient sampling method was used. All cases of cervical cancer diagnosed within the last 36 months and reporting to the out-patient department or admitted in the ward on surgical treatment, radiotherapy, chemoradiation, chemotherapy, palliative treatment were taken for the study after consent. Patient's whose diagnosis was not clear about the origin of the tumour were excluded from the study.

Sample size was estimated using the following formula:

$$
\begin{aligned}
& \mathrm{n}=\mathrm{Z}^{2} \times \mathrm{p} \times \mathrm{q} / \mathrm{e}^{2} \\
& =(1.96)^{2} \times 0.81 \times(1-0.81) /(0.07)^{2} \\
& =121 \\
& \text { Where, } \\
& \mathrm{n}=\text { minimum required sample size } \\
& \mathrm{Z}=1.96 \text { at } 95 \% \text { Confidence Interval } \\
& \mathrm{p}=\text { prevalence from previous study, } 0.81^{4} \\
& \mathrm{q}=1-\mathrm{p} \\
& \mathrm{e}=\text { margin of error }, 7 \%
\end{aligned}
$$

Adding the $10 \%$ non-response rate the final sample size was 133. However, the total number of cases enrolled in the study was 142 .

The information was collected by interview regarding the demographic factors such as age at diagnosis, menopausal status at diagnosis, marital status, parity, place of residence, distance from the health facility, education level and clinical factors such as initial symptoms of cervical cancer, history of screening for cervical cancer, history of smoking and health-seeking interval. The record was checked regarding the type of tumour and stage at diagnosis of cervical cancer. Details of the treatment received were noted. The stage at diagnosis was divided as early-stage for Stages I to IIA and late-stage for Stages IIB to IV.

The collected data were entered and analysed in SPSS (Statistical Package for Social Sciences) version 20. Descriptive statistics were used and the categorical variables were interpreted by frequencies and percentages. Continuous variables were summarized into means with standard deviations.

\section{RESULTS}

Out of the 142 cases of diagnosed cervical cancer, 93 $(65.5 \%)(57.7-73.3$ at $95 \%$ Confidence Interval) were of late-stage (IIB-IV) cervical cancer. The mean age

\begin{tabular}{|c|c|}
\hline Demographic Factors & n (\%) \\
\hline \multicolumn{2}{|l|}{ Age at diagnosis (years) } \\
\hline$<40$ & $23(16.2)$ \\
\hline $40-49$ & 45 (31.7) \\
\hline$\geq 50$ & $74(52.1)$ \\
\hline \multicolumn{2}{|l|}{ Menopausal at diagnosis } \\
\hline Yes & $75(52.8)$ \\
\hline No & $67(47.2)$ \\
\hline \multicolumn{2}{|l|}{ Marital status } \\
\hline Married & $116(81.7)$ \\
\hline Unmarried & 0 \\
\hline Separated & $4(2.8)$ \\
\hline Divorced & $33(15.2)$ \\
\hline Widowed & 0 \\
\hline \multicolumn{2}{|l|}{ Parity } \\
\hline 1 & $3(2.1)$ \\
\hline $2-4$ & $107(71.8)$ \\
\hline$\geq 5$ & $32(22.5)$ \\
\hline \multicolumn{2}{|l|}{ Place of residence } \\
\hline Kathmandu valley & $40(28.2)$ \\
\hline Outside Kathmandu & $102(71.8)$ \\
\hline \multicolumn{2}{|c|}{ Distance from a health facility $(\mathrm{km})$} \\
\hline$<50$ & $42(29.6)$ \\
\hline $50-100$ & $26(18.3)$ \\
\hline$>100$ & $74(52.1)$ \\
\hline \multicolumn{2}{|l|}{ Education level } \\
\hline Illiterate & $83(58.5)$ \\
\hline Primary (class 1-5) & $39(27.5)$ \\
\hline Secondary (6-12) & $20(14.1)$ \\
\hline Higher secondary and above & $0(0)$ \\
\hline
\end{tabular}
at diagnosis of cervical cancer was $50.6 \pm 10.9$ years ranging from 30 to 78 years. Most of the women were above 50 years $74(52.1 \%)$ and postmenopausal 75
$(52.8 \%)$ at diagnosis. The mean parity was $3.6 \pm 1.8$. More than two-thirds of the women were from outside Kathmandu valley $102(71.8 \%)$ and came from $>50 \mathrm{~km}$ distance. The majority of the women 83 (58.5\%) were illiterate (Table 1).

Among the clinical factors, abnormal vaginal bleeding was the most common initial symptom present in 117 (82.4\%) women. Among them, 36 (25.4\%) had intermenstrual and $23(16.2 \%)$ had post-coital bleeding. Among the 75 postmenopausal ladies, 58 (77.3\%) had postmenopausal bleeding. Squamous cell carcinoma was present in 129 (90.8\%) women. Four women $(2.8 \%)$ had no symptoms at all. Only $16(11.3 \%)$ had a history of screening. Fifty nine $(41.5 \%)$ had delayed health-seeking interval ( $\geq 3$ months) after initial symptoms (Table 2). On further questioning, the most common reason for the delayed health-seeking interval was, not taking it as a serious problem 32 (54.2\%), 
Ojha et al. Late Stage Cervical Cancer among Confirmed Cervical Cancer Cases in a Tertiary Care Centre: A Descriptive Cross-sectional Study...

followed by financial reason $11(18.7 \%)$ and lockdown due to Covid19 pandemic $11(18.7 \%)$, few sought traditional healers $3(5.1 \%)$ or had fear of diagnosis in $2(3.4 \%)$ women.

\begin{tabular}{|lc|}
\hline $\begin{array}{l}\text { Table 2. Clinical characteristics } \\
\text { cases }(\mathbf{n}=\text { of }\end{array}$ cervical cancer \\
\hline Clinical Factors & $\mathbf{n}(\%)$ \\
Initial symptoms* & \\
Abnormal vaginal bleeding & $117(82.4)$ \\
Abnormal vaginal discharge & $91(64.1)$ \\
Pain lower abdomen/pelvic pain & $56(39.4)$ \\
None & $4(2.8)$ \\
History of screening for cervical cancer & \\
Yes & $16(11.3)$ \\
No & $122(85.9)$ \\
Don't know & $4(2.8)$ \\
History of smoking & \\
Yes & $49(35.5)$ \\
No & $93(65.5)$ \\
Health seeking interval & \\
$<3$ months & $83(58.5)$ \\
$\geq 3$ months & $59(41.5)$ \\
Histopathology report & $129(90.8)$ \\
Squamous cell & $13(9.2)$ \\
\hline Adenocarcinoma &
\end{tabular}

*May have more than one response

Table 3 shows the distribution of late-stage presentation of cervical cancer in different demographic factors. According to the education level, 31 (52.5\%) literates had late-stage, while among the illiterate women 62 $(74.7 \%)$ were in late-stage at presentation (Table 3$)$.

\begin{tabular}{|c|c|c|}
\hline \multicolumn{3}{|c|}{$\begin{array}{l}\text { Table 3. Distribution of late-stage presentation } \\
\text { cervical cancer among different demographic factor } \\
(n=142) \text {. }\end{array}$} \\
\hline \multirow[t]{2}{*}{ Demographic factors } & \multicolumn{2}{|c|}{ Late-stage at diagnosis } \\
\hline & Yes n (\%) & No $n(\%)$ \\
\hline \multicolumn{3}{|l|}{ Age at diagnosis (years) } \\
\hline$<50$ & $42(61.8)$ & $26(38.2)$ \\
\hline$\geq 50$ & $51(68.1)$ & $23(31.9)$ \\
\hline \multicolumn{3}{|c|}{ Menopausal at diagnosis } \\
\hline No & $42(62.7)$ & $25(37.3)$ \\
\hline Yes & $52(68.0)$ & $24(32.0)$ \\
\hline \multicolumn{3}{|l|}{ Marital status } \\
\hline Married & $75(64.1)$ & $42(35.9)$ \\
\hline Separated/Widowed & $18(72.0)$ & $7(28.0)$ \\
\hline \multicolumn{3}{|l|}{ Parity } \\
\hline$\leq 4$ & $68(62.4)$ & $41(37.6)$ \\
\hline$>4$ & $25(75.8)$ & $8(24.2)$ \\
\hline \multicolumn{3}{|l|}{ Place of residence } \\
\hline Kathmandu valley & $22(55.0)$ & $18(45.0)$ \\
\hline Outside Kathmandu & $71(69.6)$ & $31(30.4)$ \\
\hline \multicolumn{3}{|c|}{ Distance from a health facility $(\mathrm{Km})$} \\
\hline$<50$ & $24(57.1)$ & $18(42.9)$ \\
\hline$\geq 50$ & $69(69.0)$ & $31(31.0)$ \\
\hline
\end{tabular}

\begin{tabular}{|lll|} 
Education level & & \\
Literate & $31(52.5)$ & $28(47.5)$ \\
Illiterate & $62(74.7)$ & $21(25.3)$ \\
\hline
\end{tabular}

The distribution of late-stage presentation of cervical cancer in different clinical factors is shown (Table 4).

\begin{tabular}{|c|c|c|}
\hline \multirow[t]{2}{*}{ Clinical factors } & \multicolumn{2}{|c|}{ Late-stage at diagnosis } \\
\hline & Yes n (\%) & No $n(\%)$ \\
\hline \multicolumn{3}{|c|}{$\begin{array}{l}\text { The initial symptom of Abnormal vaginal bleeding } \\
(n=142)\end{array}$} \\
\hline No & $12(48.0)$ & $13(52.0)$ \\
\hline Yes & $81(66.4)$ & $36(30.8)$ \\
\hline \multicolumn{3}{|c|}{ Postmenopausal bleeding $(n=75)$} \\
\hline No & $10(55.6)$ & $8(44.4)$ \\
\hline Yes & $39(70.9)$ & $16(29.1)$ \\
\hline \multicolumn{3}{|c|}{ History of screening for cervical cancer $(n=138)$} \\
\hline Yes & $8(50.0)$ & $8(50.0)$ \\
\hline No & $81(66.4)$ & $41(33.6)$ \\
\hline \multicolumn{3}{|c|}{ History of smoking $(n=142)$} \\
\hline No & $59(63.4)$ & $34(36.6)$ \\
\hline Yes & $34(69.4)$ & $15(30.6)$ \\
\hline \multicolumn{3}{|c|}{ Health seeking interval $(n=142)$} \\
\hline$<3$ months & $45(54.2)$ & $38(45.8)$ \\
\hline$\geq 3$ months & $48(81.4)$ & $11(18.6)$ \\
\hline \multicolumn{3}{|c|}{ Histology of tumour $(n=142)$} \\
\hline Adenocarcinoma & $5(38.5)$ & $8(61.5)$ \\
\hline Squamous carcinoma & $88(68.2)$ & $41(31.8)$ \\
\hline
\end{tabular}

\section{DISCUSSION}

This study was conducted in a hospital in Kathmandu, Nepal and explored the late-stage presentation of cervical cancer. Of the total cervical cancer cases, 93 $(65.5 \%)$ women presented in late-stage. It is similar to most of the studies done in developing countries, which shows the majority of the cervical cancer cases diagnosed, were in the late-stage ranging from 65 to $80 \%$ as compared to the early stage. ${ }^{4,8,10}$ Mlange, et al. found among 202 patients confirmed with cervical cancer, the prevalence of late-stage cervical cancer was $63.9 \% .{ }^{11}$ Studies have shown that late-stage at diagnosis is correlated with lower survival rates in cervical cancer patients. ${ }^{12}$ Approximately $84 \%$ of all cervical cancers and $88 \%$ of all deaths caused by cervical cancer occurred in lower-resource countries, by contrast, in highest-resource countries, the cumulative rate of cervical cancer and mortality were two to four times lower than those in lower resource countries. ${ }^{1}$

The mean age of the women at diagnosis was $50.6 \pm 10.9$ ) years. It is similar to other studies where the mean age of the women presenting to the hospital at diagnosis of cervical cancer ranged from 50-53 years. ${ }^{4,11,13,14}$ Higher age is associated with advancedstage cervical cancer. The proportion of advanced 
Ojha et al. Late Stage Cervical Cancer among Confirmed Cervical Cancer Cases in a Tertiary Care Centre: A Descriptive Cross-sectional Study...

stage in new invasive cervical cancer was $30 \%$ among women aged $<50$ years and $52 \%$ among women aged $\geq 50$ years. ${ }^{15}$ However, in the present study, older age is not associated with the late-stage presentation of cervical cancer as in other studies. ${ }^{4,10,11}$

This study, among the socio-demographic characteristics of the patients, showed that illiterate women were more likely to have late-stage (illiterate $74.7 \%$ vs literate $52.5 \%)$. Studies from Uganda, ${ }^{8}$ Iran, ${ }^{6} \mathrm{Nepal}^{4}{ }^{4}$ suggest that delayed diagnosis of cervical cancer was higher in women with lower-level education. The lower level of education may be indirectly related to lower socioeconomic status, ignorance about the preventive measures as screening which can adversely affect in delay in seeking healthcare.

A systematic review of research on the association between marital status and stage at diagnosis of different types of cancer showed a significant association between marital status and stage at diagnosis, with a positive effect of marriage on the cancer being diagnosed in the earlier stage. ${ }^{16}$ Married women tend to have better health-seeking behaviour. ${ }^{17}$ In a study from Morocco, women who were not married were more likely to present in late-stage cancer. ${ }^{7}$ In the present study, $116(81.7 \%)$ of the women were married and those separated/widows were more likely to have a late-stage diagnosis in comparison to married women $(70.0 \%$ vs $64.1 \%$ respectively).

Place of residence or distance from health facility plays an important factor for earlier presentation. Women living at a further distance were more in late-stage it. Women who live more than $100 \mathrm{~km}$ from the location of cancer diagnosis site were four times more likely to present late $(\mathrm{OR}=4.51 ; 95 \% \mathrm{Cl}: 1.35-15.11),{ }^{7}$ and women living in the rural community were more likely to have delayed diagnosis. ${ }^{14,18}$

The present study showed only $16(11.3 \%)$ had a history of screening for cervical cancer. Among the screened women $50 \%$ had late-stage diagnosis while in an unscreened group it was $66.4 \%$, however, the number of cases was quite low. The health delivery system of the country is complex as screening as well as early detection and treatment facilities are concentrated in the major cities and especially in the Kathmandu valley. Studies from national household surveys and communities in Nepal show low knowledge and practice regarding cervical cancer screening. ${ }^{19,20}$ Previously unscreened cases of cervical cancer were nearly four times more likely to present late, compared to those who had been screened previously. ${ }^{10}$ Factors that contribute to the late diagnosis are inadequate knowledge of cervical cancer, lack of screening, and poor diagnostic procedure and treatment among health care providers. ${ }^{21}$

The most common initial symptom was abnormal vaginal bleeding present in $82.4 \%$ of cases. The symptom may have prompted the women to seek healthcare but by the time the women become symptomatic she may be in late-stage, which was higher in a late-stage presentation in the present study. A similar finding was seen in another study from Nepal, ${ }^{4}$ but not in other study. ${ }^{10}$

Delayed health-seeking behaviour has been adversely associated with the late-stage presentation of cervical cancer. Reasons for the delayed presentation were, not taking the symptoms as being serious (54.2\%), financial reason $(18.7 \%)$, or lockdown due to Covid19 pandemic in $18.7 \%$. It is intricately associated with the educational status, socioeconomic status, distance to the healthcare centre and knowledge related to cervical cancer. ${ }^{13}$ In our study, 59 (41.5\%) had sought healthcare after three months of initial symptoms, who were more likely to present in late-stage $181.2 \%$ vs $54.2 \%$ ) as compared to those who presented earlier. It is similar to another study where longer healthseeking intervals were associated with more advanced cancer stages at pathological diagnosis. ${ }^{18}$

In the present study, squamous cell histology was present in $90.8 \%$ of cases. Squamous cell carcinoma accounts for three fourth of cervical cancer. SEER data from the USA suggest an increasing prevalence of adenocarcinoma of the cervix with a poorer prognosis, which could be due to the inefficiency of conventional screening for these tumours. ${ }^{12}$ Cervical cancer predominantly coming in late-stage could be due to women coming only after being symptomatic, rather than during screening program.

The sample size is not very large and there could have been memory bias during the interview. The present study represented many districts of Nepal as it was done in a tertiary care referral cancer hospital where women from all over Nepal come for treatment.

\section{CONCLUSIONS}

The study provides information on the prevalence of late-stage cervical cancer. The late-stage presentation of cervical cancer was almost the same in comparison to a similar study done in similar settings. It was found in higher proportion in older and postmenopausal women, higher parity, living outside Kathmandu valley, illiterate. Having abnormal vaginal bleeding, lack of screening delayed health-seeking intervals all led to the latestage presentation of cervical cancer. As two-third of the women presented in an advanced stage, provision of an organized screening program and diagnosis and treatment of cervical cancer in early-stage would 
Ojha et al. Late Stage Cervical Cancer among Confirmed Cervical Cancer Cases in a Tertiary Care Centre: A Descriptive Cross-sectional Study...

ultimately improve the survival of the women.

\section{REFERENCES}

1. Arbyn M, Weiderpass E, Bruni L, de Sanjose S, Saraiya M, Ferlay J, et al. Estimates of incidence and mortality of cervical cancer in 2018: a worldwide analysis. Lancet Glob Health. 2020 Feb;8(2):e191-203. [PubMed | Full Text | DOI]

2. Poudel KK, Huang Z, Neupane PR, Steel R, Poudel JK. Hospital-based cancer incidence in Nepal from 2010 to 2013. Nepal J Epidemiol. 2017 Mar 31;7(1):659-65. [PubMed | Full $\underline{\text { Text }}$ | DOI]

3. Bray F, Ferlay J, Soerjomataram I, Siegel RL, Torre LA, Jemal A. Global cancer statistics 2018: GLOBOCAN estimates of incidence and mortality worldwide for 36 cancers in 185 countries. CA Cancer J Clin. 2018 Nov;68(6):394-424. [PubMed | Full Text | DOI]

4. Gyenwali D, Pariyar J, Onta SR. Factors associated with late diagnosis of cervical cancer in Nepal. Asian Pac J Cancer Prev. 2013;14(7):4373-7. [PubMed | Full Text | DOI]

5. Saghari S, Ghamsary M, Marie-Mitchell A, Oda K, Morgan JW. Sociodemographic predictors of delayed-versus early-stage cervical cancer in California. Ann Epidemiol. 2015 Apr;25(4):250-5. [uued | Full Text | DOI]

6. Behnamfar F, Azadehrah M. Factors associated with delayed diagnosis of cervical cancer in Iran--a survey in Isfahan City. Asian Pac J Cancer Prev. 2015;16(2):635-9. [PubMed | Full $\underline{\text { Text }}$ | DOI]

7. Berraho M, Obtel M, Bendahhou K, Zidouh A, Errihani H, Benider $\mathrm{A}$, et al. Sociodemographic factors and delay in the diagnosis of cervical cancer in Morocco. Pan Afr Med J. 2012;12:14. [PubMed | Full Text]

8. Mwaka AD, Garimoi CO, Were EM, Roland M, Wabinga H, et al. Social, demographic and healthcare factors associated with stage at diagnosis of cervical cancer: cross-sectional study in a tertiary hospital in Northern Uganda. BMJ Open. 2016 Jan 21;6(1):e007690. [PubMed | Full Text | DOI]

9. Ndlovu N, Kambarami R. Factors associated with tumour stage at presentation in invasive cervical cancer. Cent Afr J Med. 2003 Sep-Oct;49(9-10):107-11. [PubMed]

10. Dunyo P, Effah K, Udofia EA. Factors associated with late presentation of cervical cancer cases at a district hospital: a retrospective study. BMC Public Health. 2018 Oct 3;18(1):1156. [PubMed | Full Text |DOI]

11. Mlange R, Matovelo D, Rambau P, Kidenya B. Patient and disease characteristics associated with late tumour stage at presentation of cervical cancer in northwestern Tanzania. BMC Womens Health. 2016 Jan 25;16:5. [ubMed | Full Text I DOI]

\section{Conflict of Interest: None.}

12. Vinh-Hung V, Bourgain C, Vlastos G, Cserni G, De Ridder $M$, Storme G, et al. Prognostic value of histopathology and trends in cervical cancer: a SEER population study. BMC Cancer. 2007 Aug 23;7:164. [PubMed | Full Text | DOI]

13. Ouasmani F, Hanchi Z, HaddouRahou B, Bekkali R, Ahid $S$, Mesfioui A. Determinants of patient delay in seeking diagnosis and treatment among Moroccan women with cervical cancer. Obstet Gynecol Int. 2016;2016:4840762. [PubMed | Full Text $\mid \underline{\text { DOI] }}$

14. Zeleke S, Anley M, Kefale D, Wassihun B. Factors Associated with delayed diagnosis of cervical cancer in Tikur Anbesa specialized hospital, Ethiopia, 2019: cross-sectional study. Cancer Manag Res. 2021 Jan 22;13:579-85. [PubMed | Full Text | DOI]

15. Centers for Disease Control and Prevention (CDC). Invasive cervical cancer among Hispanic and non-Hispanic women--United States, 1992-1999. MMWR Morb Mortal Wkly Rep. 2002 Nov 29;51(47):1067-70. [PubMed | Full Text]

16. Buja A, Lago L, Lago S, Vinelli A, Zanardo C, Baldo V. Marital status and stage of cancer at diagnosis: A systematic review. Eur J Cancer Care (Engl). 2018 Jan;27(1). [람ed | Full Text | DOI]

17. Reddy PMC, Rineetha T, Sreeharshika D, Jothula KY. Health care seeking behaviour among rural women in Telangana: A cross sectional study. J Family Med Prim Care. 2020 Sep 30;9(9):4778-83. [․ㅏbMed | Full Text | DOI]

18. Begoihn M, Mathewos A, Aynalem A, Wondemagegnehu T, Moelle U, Gizaw M, et al. Cervical cancer in Ethiopia - predictors of advanced stage and prolonged time to diagnosis. Infect Agent Cancer. 2019 Nov 11;14:36. [PubMed | Full Text | DOI]

19. Ranjit A, Gupta S, Shrestha R, Kushner AL, Nwomeh BC, Groen RS. Awareness and prevalence of cervical cancer screening among women in Nepal. Int J Gynaecol Obstet. 2016 Jul;134(1):37-40. [uㅏMed | Full Text | DOI]

20. Shakya S, Karmacharya BM, Afset JE, Bofin A, Asvold $\mathrm{BO}$, Syversen $\mathrm{U}$, et al. Community-based health education has positive influence on the attitude to cervical cancer screening among women in rural Nepal. J Cancer Educ. 2016 Sep;31(3):547-53. [ㅁuMed | Full Text | DOI]

21. Tran NT, Taylor R, Choe SI, Pyo HS, Kim OS, So HC. Knowledge, attitude and practice (KAP) concerning cervical cancer and screening among rural and urban female healthcare practitioners in the Democratic People's Republic of Korea. Asian Pac J Cancer Prev. 2011;12(11):3023-8. [PubMed | Full Text]

The Author(s) 2018

This work is licensed under a Creative Commons Attribution 4.0 International License. The images or other third party material in this article are included in the article's Creative Commons license, unless indicated otherwise in the credit line; if the material is not included under the Creative Commons license, users will need to obtain permission from the license holder to reproduce the material. To view a copy of this license, visit http://creativecommons.org/licenses/by/4.0/ 